\title{
Thrombotic Thrombocytopenic Purpura in a Case of Dengue Fever: A Rare Presentation
}

\author{
Abhijit S. Gavali, Jayant Shelgaonkar, Sandip Bartakke' \\ Departments of Critical Care Medicine and 'Department of Hematology, Aditya Birla Memorial Hospital, Pune, Maharashtra, India
}

\section{Abstract}

Here, we present an unusual occurrence of thrombotic thrombocytopenic purpura (TTP) in a case of dengue fever. Both the conditions are fatal and can result in significant mortality and morbidity if left untreated. In this case, as soon as, we diagnosed the patient as having TTP, we treated her with plasma exchange therapy, steroids, and monoclonal antibodies such as rituximab. The patient responded very well to the treatment and completely recovered from neurological symptoms and laboratory parameters also normalized. Hence, timely diagnosis and starting appropriate treatment immediately are key factors for successful outcome.

Keywords: ADAMTS13, dengue fever, plasma exchange therapy, rare case presentation, thrombotic thrombocytopenic purpura

\section{INTRODUCTION}

Thrombotic thrombocytopenic purpura (TTP) is a rare disorder with an incidence of $4-5$ cases per million per year. It has significant morbidity and mortality if left untreated. Timely diagnosis and availability of effective treatment such as plasma exchange therapy have reduced the morbidity and mortality significantly. Usually, it is idiopathic or autoimmune, but several predisposing factors have been described to cause secondary TTP. In this case report, we discussed a very rare presentation of TTP secondary to dengue virus infection and how the timely diagnosis along with the immediate institution of appropriate management helped us to cure the patient.

\section{Case Report}

A 35-year-old female with no other comorbidities was admitted to the hospital with complaints of fever and vomiting over 1 week. Her investigations revealed a low platelet count and dengue IgG, and IgM antibodies were positive. She was symptomatically treated at a local hospital and was transfused 16 units of random donor platelets over a period of 6 days. But despite this, platelet count was remaining low. Her consciousness deteriorated on the $6^{\text {th }}$ day of hospital stay. Hence, she was shifted to our tertiary care center.

\begin{tabular}{|l|l|}
\hline \multicolumn{2}{|c|}{ Access this article online } \\
\hline Quick Response Code: & Website: \\
\hline & www.ijccm.org \\
\hline & \\
\hline
\end{tabular}

On arrival, the patient was drowsy, arousable to verbal commands only, and had decreased limb movement on the right side. Laboratory investigations were showing anemia, thrombocytopenia, and increased lactate dehydrogenase (LDH) level as shown in Table 1. Her peripheral blood smear revealed numerous schistocytes and computed tomography (CT) brain was unremarkable. Ultrasonography abdomen was suggestive of bulky kidneys, and she was retrovirus negative.

With this clinical picture and laboratory findings, she was diagnosed as a case of TTP and was advised urgent plasma exchange therapy. Although there is no firm recommendation for administration of steroids in TTP, we started her on low-dose injection methylprednisolone (100 mg daily) considering its autoimmune etiology. Plasmapheresis was done daily with approximately $2-2.5 \mathrm{~L}$ plasma exchange. On the $2^{\text {nd }}$ day of the admission, she had an episode of convulsion which was treated with anticonvulsive medication. She required intubation and ventilatory support because of postconvulsion low Glasgow Coma Scale (GCS).

$$
\begin{aligned}
& \text { Address for correspondence: Dr. Abhijit S. Gavali, } \\
& \text { Department of Critical Care Medicine, Aditya Birla Memorial Hospital, } \\
& \text { Pune, Maharashtra, India. } \\
& \text { E-mail: dr.abhi1311@gmail.com }
\end{aligned}
$$

This is an open access article distributed under the terms of the Creative Commons Attribution-NonCommercial-ShareAlike 3.0 License, which allows others to remix, tweak, and build upon the work non-commercially, as long as the author is credited and the new creations are licensed under the identical terms.

For reprints contact: reprints@medknow.com

How to cite this article: Gavali AS, Shelgaonkar J, Bartakke S. Thrombotic thrombocytopenic purpura in a case of dengue fever: A rare presentation. Indian J Crit Care Med 2017;21:226-8. 


\begin{tabular}{|c|c|c|c|c|c|c|c|c|}
\hline & Day 1 & Day 2 & Day 3 & Day 4 & Day 5 & Day 7 & Day 9 & Day 12 \\
\hline Hemoglobin(g/dl) & 6.1 & 7.7 & 7.4 & 5.7 & 7.1 & 7.3 & 8.2 & 8.3 \\
\hline WBC & 5.9 & 6.2 & 12.6 & 9.5 & 7.8 & 12.6 & 8.6 & 5.8 \\
\hline Platelet (mm3) & 7000 & 9000 & 6000 & 15000 & 17000 & 42000 & $1,01,000$ & $1,02,000$ \\
\hline Creatinine $(\mathrm{mg} / \mathrm{dl})$ & 0.7 & 0.6 & - & 0.5 & - & - & - & 0.4 \\
\hline LDH(U/L) & 5000 & - & 1284 & - & 858 & - & - & 511 \\
\hline
\end{tabular}

Her antinuclear antibody result was negative. She convulsed again on $3^{\text {rd }}$ day with drop in hemoglobin and platelets [Table 1], so injection rituximab $500 \mathrm{mg}$ was added to treatment in addition to plasma exchange. Her CT scan of the brain was repeated which revealed no significant abnormality. Daily plasma exchange was continued. Her general condition started improving from $4^{\text {th }}$ day of hospital stay. Platelet count improved, serum LDH level showed decline over a period [Table 1]. She was extubated on the $8^{\text {th }}$ day. She underwent total eight plasmapheresis cycles, and before discharge, her platelet counts were $152 \mathrm{~mm}^{3}$, serum LDH was $511 \mathrm{U} / \mathrm{L}$. She was conscious with GCS of 15/15 and without any sensory-motor deficit. We followed her up in the outpatient department, and at 6 months, she is well with normal hemogram.

\section{RESULT}

This patient had dengue viral infection confirmed by serology which was complicated by TTP during the acute phase of dengue viral infection. We diagnosed this by clinical features and ruling out other differential diagnosis by laboratorial and radiological tests. The patient responded well to the plasma exchange therapy with complete recovery from symptoms and no recurrence after 6 months follow-up.

\section{Discussion}

Dengue is most rapidly spreading mosquito-borne viral disease in the world. There is a global pandemic with worldwide distribution. ${ }^{[1]}$ This infection has potential to cause significant morbidity and mortality. ${ }^{[2]}$ Usually, it presents as mild/asymptomatic type of infection; however, at times, it may manifest in more severe forms such as dengue hemorrhagic fever, or dengue shock syndrome. ${ }^{[3]}$ Many unusual complications have been observed with dengue viral infection such as hepatic damage, cardiomyopathy, and encephalopathy. ${ }^{[4]}$ The presence of TTP with dengue viral infection is very rare presentation and has been reported in very few case reports. ${ }^{[5,6]}$

TTP itself is a rare clinical syndrome characterized by fever, microangiopathic hemolytic anemia, thrombocytopenia, central nervous system involvement, and renal impairment. However, all five features are observed in only $40 \%$ of patients. ${ }^{[7]}$ Secondary TTP can occur after infections, medications (e.g., clopidogrel, cyclosporine), autoimmune diseases, malignancies, pregnancy, and bone marrow transplantation. ${ }^{[8]}$ Infections known to cause thrombotic microangiopathy include hepatitis C, parvovirus B19 virus infection, HIV infection as well as patient with dental foci or streptococci infection. ${ }^{[9-13]}$ Pathophysiology of TTP includes deficiency of protease enzyme (ADAMTS13) that cleaves von Willebrand factor (vWF) in small segments. In the absence of ADAMTS13 enzyme, large vWF cause platelet aggregation and fibrin deposition in small vessels and result in microthrombi.

In our case, the patient was diagnosed as having dengue viral infection by the presence of IgM and IgG antibodies and treated accordingly with fluid resuscitation and platelet transfusion. But later, the patient showed features such as fever, thrombocytopenia, hemolytic anemia, and neurological involvement in the form of decreased consciousness, hemiparesis, and seizures (CT brain-normal). All these features were suggestive of TTP and patient responded well to plasma exchange therapy, steroid therapy, and injection rituximab.

\section{Conclusion}

Although the exact incidence of TTP in dengue viral infection is not known, such cases are reported in the recent past. Hence, special attention must be given to dengue virus infection patients presenting with signs and symptoms of TTP in the future. The prompt clinical recognition of such complication and early initiation of specific therapy with plasma exchange is likely to improve the patient's outcome.

\section{Financial support and sponsorship}

Nil.

\section{Conflicts of interest}

There are no conflicts of interest.

\section{References}

1. Guzmán MG. Global voices of science. Deciphering dengue: The Cuban experience. Science 2005;309:1495-7.

2. Rigau-Pérez JG, Clark GG, Gubler DJ, Reiter P, Sanders EJ, Vorndam AV. Dengue and dengue haemorrhagic fever. Lancet 1998;352:971-7.

3. Guzmán MG, Kourí G. Dengue: An update. Lancet Infect Dis 2002;2:33-42.

4. Wichmann O, Gascon J, Schunk M, Puente S, Siikamaki H, Gjørup I, et al. Severe dengue virus infection in travelers: Risk factors and laboratory indicators. J Infect Dis 2007;195:1089-96.

5. Deepanjali S, Naik RR, Mailankody S, Kalaimani S, Kadhiravan T. Dengue virus infection triggering thrombotic thrombocytopenic purpura in pregnancy. Am J Trop Med Hyg 2015;93:1028-30.

6. Rossi FC, Angerami RN, de Paula EV, Orsi FL, Shang D, del Guercio VM, et al. A novel association of acquired ADAMTS13 inhibitor and acute dengue virus infection. Transfusion 2010;50:208-12.

7. Murrin RJ, Murray JA. Thrombotic thrombocytopenic 
purpura: Aetiology, pathophysiology and treatment. Blood Rev 2006;20:51-60.

8. Qasim ZA, Partridge RA. Thrombotic thrombocytopenic purpura presenting as bilateral flank pain and hematuria: A case report. J Emerg Med 2001;21:15-20.

9. Kok RH, Wolfhagen MJ, Klosters G. A syndrome resembling thrombotic thrombocytopenic purpura associated with human parvovirus B19 infection. Clin Infect Dis 2001;32:311-2.

10. Yagita $M$, Uemura $M$, Nakamura $T$, Kunitomi A, Matsumoto $M$, Fujimura Y. Development of ADAMTS13 inhibitor in a patient with hepatitis $\mathrm{C}$ virus-related liver cirrhosis causes thrombotic thrombocytopenic purpura. J Hepatol 2005;42:420-1.

11. Morrin MJ, Jones FG, McConville J, Arnold C, Mullan B, Lavery GG, et al. Thrombotic thrombocytopenic purpura secondary to Streptococcus. Transfus Apher Sci 2006;34:153-5.

12. Gunther K, Garizio D, Nesara P. ADAMTS13 activity and the presence of acquired inhibitors in human immunodeficiency virus-related thrombotic thrombocytopenic purpura. Transfusion 2007;47:1710-6.

13. Brecher ME, Hay SN, Park YA. Is it HIV TTP or HIV-associated thrombotic microangiopathy? J Clin Apher 2008;23:186-90. 